\title{
Sonographic evaluation of the axillary artery during simulated overhead throwing arm positions
}

\author{
Claire Stapleton $^{\mathrm{a}, *}$, Lee Herrington ${ }^{\mathrm{b}}$, Keith George ${ }^{\mathrm{a}}$ \\ ${ }^{a}$ Research Institute for Sport and Exercise Sciences, Liverpool John Moores University, Liverpool, UK \\ ${ }^{\mathrm{b}}$ Centre for Rehabilitation and Human Performance Research, University of Salford, Salford, UK \\ Received 19 February 2008; received in revised form 5 June 2008; accepted 12 June 2008
}

\begin{abstract}
Objectives: The aim of this study was to determine changes in axillary artery diameter and peak systolic velocity in asymptomatic individuals during upper limb positioning commonly used to assess vascular pathology in athletes.

Design: Repeated measures observational study.

Setting: Physiology laboratory.

Participants: Subjective and objective screening excluded individuals with past, or present, conditions related to neurovascular compression syndromes. Thirty-one subjects ( 21 females, 10 males; mean age: $25 \pm 4$ years) were included in the final analysis.

Main outcome measures: Sonographically determined axillary artery diameter and peak systolic velocity, as well as symptom production, were recorded for a series of 12 randomised arm positions, incorporating varying degrees of abduction, external rotation, and horizontal flexion/extension.

Results: The majority of arm positions revealed no change in artery diameter and peak systolic velocity. However, at the extreme of abduction, and arm positions incorporating $120^{\circ}$ abduction, significant $(p<0.0005)$ reductions in axillary artery diameter were noted. All mean results masked wide heterogeneity: 13\% demonstrating a greater than $50 \%$ reduction in diameter, $10 \%$, a doubling of peak systolic velocity, and $42 \%$, reporting symptoms.

Conclusions: The number of individual clinically "positive" responses questions the specificity of individual diagnostic tests, such as the hyperabduction manoeuvre, and highlights the need to interpret test results in conjunction with the subjective assessment and other physical findings from the objective assessment.
\end{abstract}

(C) 2008 Elsevier Ltd. All rights reserved.

Keywords: Ultrasonography; Diagnosis; Physical examination; Axillary artery

\section{Introduction}

The majority of vascular compression syndromes affecting the upper limb come under the 'umbrella term' of thoracic outlet syndrome with most published reports focusing on the more commonly compressed subclavian artery, vein or surrounding neural structures (Demondion, Herbinet, Gautier, Duquesnoy, \& Cotton, 2006; Gillard

\footnotetext{
*Corresponding author. Tel.: + 441512314323 ; fax: + 441512314353 .

E-mail address: c.stapleton@2005.ljmu.ac.uk (C. Stapleton).
}

et al., 2001). Descriptions of the syndrome inconsistently include compression of the first and second portions of the axillary artery in the costoclavicular and retro-pectoralis minor space, respectively. Less often mentioned is the third portion of the axillary artery that lies anterior and inferior to the head of the humerus. This investigation focuses on this latter portion, and aims to raise awareness of its potential for injury and highlight the dilemmas of diagnosis.

Compressive injury of the axillary artery most commonly occurs in athletes performing repetitive overhead arm motion (Jackson, 2003). Published reports 
of such injury include baseball pitchers, handball, tennis, and volleyball players (Arko, Harris, Zarins, \& Olcott, 2001; Fields, Lemak, \& Benmenachem, 1986; Ishitobi et al., 2001; Rohrer, Cardullo, Pappas, Phillips, \& Wheeler, 1990; Todd, Benvenisty, Hershon, \& Bigliani, 1998; Vlychou, Spanomichos, Chatziioannou, Georganas, \& Zavras, 2001). The proposed mechanisms for compressive trauma of the second and third portions of the axillary artery are a tight or hypertrophied pectoralis minor muscle (Dijkstra \& Westra, 1978; Finkelstein \& Johnston, 1993) and anterior translation of the humeral head (Dijkstra \& Westra, 1978; Durham, Yao, Pearce, Nuber, \& McCarthy, 1995; Vlychou et al., 2001) combined with repetitive overhead activity.

The hyperaduction manoeuvre (Wright, 1945) is used in conjunction with the clinical presentation and subjective history to aid the diagnosis of compressive injury of the axillary artery (Demondion et al., 2006). It is thought to compressively stress the vessels in the subcoracoid region, especially the second portion of the axillary artery under the pectoralis minor muscle (Baker \& Liu, 1993). Clinically, it is postulated that this manoeuvre stresses the vasculature to accurately reproduce the signs (e.g., radial pulse disappearance) and symptoms (e.g., ischaemic pain, paraesthesia, anaesthesia, heaviness) of vascular compromise. Published case studies have used advanced imaging techniques (i.e., arteriograms, angiograms, ultrasound) to confirm suspected vascular compromise of the axillary artery and its branches, with patency of the arteries in a neutral upper limb position compared to a stenosed or occluded vessel in the hyperabducted position (Arko et al., 2001; Cormier, Matalon, \& Wolin, 1988; Fields et al., 1986; Ishitobi et al., 2001; Kee et al., 1995; Nijhuis \& MullerWiefel, 1991; Redler, Ruland, \& McCue, 1986; Reekers, den Hartog, Kuyper, Kromhout, \& Peeters, 1993; Rohrer et al., 1990; Schneider, Kasparyan, Altchek, Fantini, \& Weiland, 1999; Todd et al., 1998; Vlychou et al., 2001). Imaging results influence the management of the condition which, in many cases, results in surgery. It is, therefore, important for clinicians to be aware that vessel occlusion has been demonstrated not only in symptomatic but in asymptomatic subjects as well. For example, Mochizuki et al. (1994) reported posterior humeral circumflex artery occlusion in the hyperabducted position in $80 \%$ of asymptomatic subjects using magnetic resonance angiography. Rohrer et al. (1990) reported axillary artery compression in $83 \%$ of the 92 arms tested (baseball pitchers, athletes and non-athletes) but results were limited by incomplete blood flow assessments and poorly defined testing positions and subject groups. The hyperabduction manoeuvre is confused by varying descriptions in the literature; consequently, results are incomparable. Further quality investigations are still required to aid clinical diagnosis and interpretation.
Uniquely, the present study seeks to extend the knowledge of the diagnosis of compressive injury of, specifically, the third portion of the axillary artery by describing a number of arm positions rather than a specific single test. Therefore, the aims of this study are to: establish the arterial diameter (D) and peak systolic velocity (PSV) at the third portion of the axillary artery, record symptom production at various arm positions, and thus to identify the rate of responses that would, clinically, be classified as positive according to Strandness's (2002) clinical criteria.

\section{Methods}

\subsection{Subjects}

Participants were 41 healthy individuals (age range: 18-40 years) recruited via local advertising in the University. Following verbal and written briefing, subjects provided written consent to participate. Local ethical approval was granted by Liverpool John Moores University Ethics Committee. Subjective and objective screening was performed by a chartered physiotherapist to ensure conditions or injuries thought to contribute to, or predispose, a neurovascular compression syndrome and/or conditions likely to be exacerbated by the experimental procedure, were excluded. Specifically, subjects were excluded if past medical history included: previous shoulder surgery, glenohumeral joint dislocations and/or subluxations, fractures to the humerus, clavicle and 1st-3rd ribs, inflammatory joint conditions, vascular or neurological disorders, or past or present injury to the neck, shoulder, and upper limb. Objective screening consisted of active range of motion with overpressure for cervical, thoracic, scapulo-thoracic, and glenohumeral range of movements. Two subjects were excluded through screening and a further eight were excluded due to poor clarity of the ultrasound image. The final analysis included 21 female and 10 male subjects with a cohort age range of 19-35 years (mean \pm S.D.: $25 \pm 4$ years). Subjects were regarded as "non-overhead throwing active individuals" based on questions related to participation levels in general activity and specific overhead activities such as, racquet sports, swimming, and rock climbing. All subjects reported right hand dominance.

\subsection{Subject position and standardisation}

With the subject seated and the right arm supported on a purpose built adaptable arm-rest, anatomical landmarks were identified to aid consistent reproduction of abduction. At approximately $45^{\circ}$ abduction, the axis of a goniometer was placed over the posterior corner of 
the acromion with the static arm parallel to the spine and the moving arm placed over a line joining the axis and the mid-point between medial and lateral epicondyles. For each subject, the height of the arm-rest was adjusted and marked to indicate $90^{\circ}$ abduction and $120^{\circ}$ abduction. To determine $180^{\circ}$ abduction, the upper limb was secured to the back board of the apparatus with the humerus as close to the ear as possible. Throughout testing, blocks were secured to the arm-rest to maintain the desired degree of shoulder girdle horizontal extension/flexion and glenohumeral external rotation. To control for subclavian artery compression at the scalene triangle subjects were instructed to maintain an upright posture with a neutral head position. A large belt was secured around the subjects' thorax and the apparatus, and a visual marker at eye level was provided to aid maintenance of these positions (see Fig. 1). Subjects were assessed in $12 \mathrm{arm}$ positions (see Table 1) presented in a random order (computer generated). A rest period of 2 min (or until any signs and symptoms of altered haemodynamics had resolved) was provided between testing for each arm position.

\subsection{Data acquisition}

Following $10 \mathrm{~min}$ in seated rest a sonographic exam was performed in a consistent manner using a portable ultrasound scanner (ESOATE MyLab30cv, Italy) with a $10-15 \mathrm{MHz}$ multi-linear array ultrasound transducer. To locate the third portion of the axillary artery, the transducer, coated in water-based gel, was positioned in the axilla, anterior and inferior to the humeral head. After $30 \mathrm{~s}$ in each arm position B-mode imaging aided by colour flow mapping detected the vessel (see Fig. 2) and an optimal longitudinal view was recorded. The split-screen facility allowed the real-time B-mode image

C

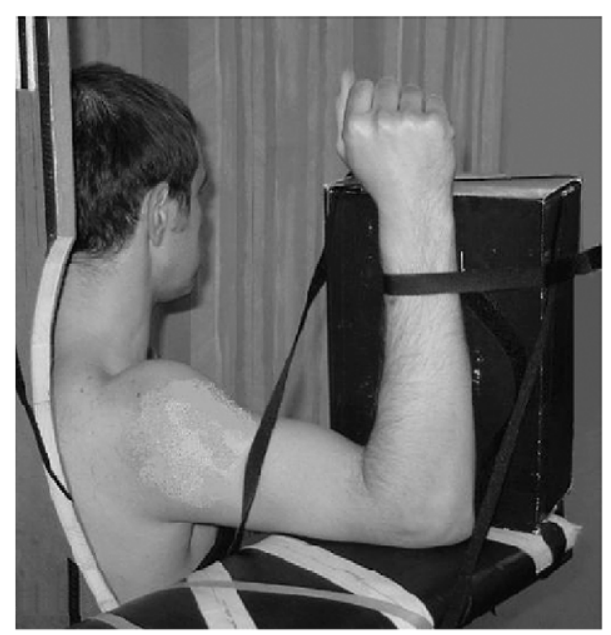

Fig. 1. Subject positioning for baseline position (a) and position 12 (b). Position (c) illustrates the use of a block to maintain $90^{\circ}$ external rotation.

Table 1

Description of arm positions and groupings for statistical comparisons for axillary artery peak systolic velocity, diameter and systolic blood pressure

\begin{tabular}{|c|c|c|c|c|c|c|c|c|c|c|}
\hline \multirow[t]{2}{*}{ APN } & \multirow[t]{2}{*}{ Arm position description } & \multicolumn{9}{|c|}{ Comparison group } \\
\hline & & A & $\mathrm{B}$ & $\mathrm{C}$ & $\mathrm{D}$ & $\mathrm{E}$ & $\mathrm{F}$ & G & $\mathrm{H}$ & I \\
\hline 1 & Approximately $45^{\circ}$ abduction & レ & レ & レ & レ & レ & レ & レ & レ & $\nu$ \\
\hline 2 & $90^{\circ}$ abduction & レ & レ & レ & & & レ & レ & & \\
\hline 3 & $120^{\circ}$ abduction & レ & & & $\nu$ & $\nu$ & & & $\nu$ & $\nu$ \\
\hline 4 & $180^{\circ}$ abduction & レ & & & & & & & & \\
\hline 5 & $90^{\circ}$ abduction, $30^{\circ}$ horizontal flexion & & レ & & & & レ & & & \\
\hline 6 & $90^{\circ}$ abduction, $30^{\circ}$ horizontal flexion, $90^{\circ}$ external rotation & & レ & & & & & レ & & \\
\hline 7 & $90^{\circ}$ abduction, $30^{\circ}$ horizontal extension & & & レ & & & レ & & & \\
\hline 8 & $90^{\circ}$ abduction, $30^{\circ}$ horizontal extension, $90^{\circ}$ external rotation & & & レ & & & & $\nu$ & & \\
\hline 9 & $120^{\circ}$ abduction, $30^{\circ}$ horizontal flexion & & & & レ & & & & レ & \\
\hline 10 & $120^{\circ}$ abduction, $30^{\circ}$ horizontal flexion, $90^{\circ}$ external rotation & & & & レ & & & & & $v$ \\
\hline 11 & $120^{\circ}$ abduction $30^{\circ}$ horizontal extension & & & & & $v$ & & & $\nu$ & \\
\hline 12 & $120^{\circ}$ abduction, $30^{\circ}$ horizontal extension, $90^{\circ}$ external rotation & & & & & レ & & & & レ \\
\hline
\end{tabular}

APN, arm position number; ' $\boldsymbol{'}$ ', inclusion of the arm position in the comparison group. 
a

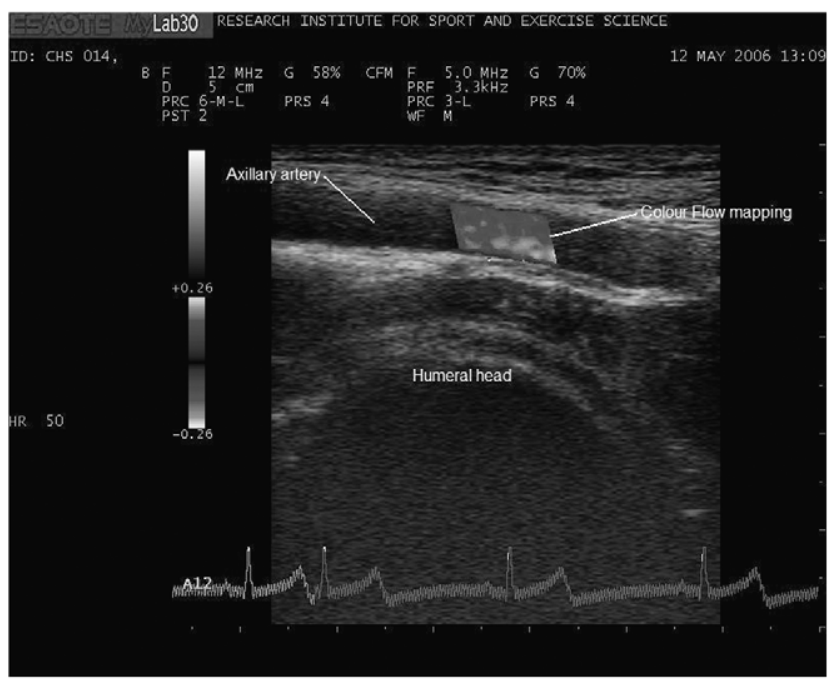

b

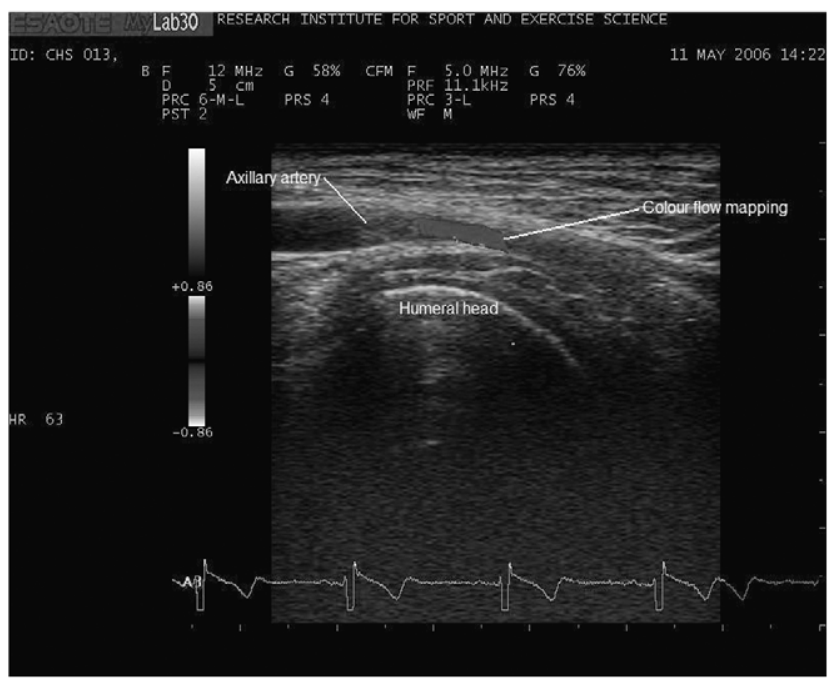

Fig. 2. B-mode ultrasound with colour flow mapping demonstrating an, (a) fully patent and (b) compressed, axillary artery.

to remain on screen while acquiring the spectral Doppler waveform for peak systolic velocity assessment. A $60^{\circ}$ angle of insonation was maintained throughout to minimise error in velocity measurement. The spectral Doppler waveform was recorded over 3-5 consecutive cardiac cycles and mean PSV $\left(\mathrm{cm} \mathrm{s}^{-1}\right)$ was determined from automated waveform analysis. Axillary artery diameter $(\mathrm{mm})$ was calculated using electronic callipers on B-mode longitudinal images of the vessel. The accuracy of measurement in B mode for distance $(\mathrm{mm})$ is reported by ESAOTE as $\pm[1.5 \% \times$ depth $(\mathrm{mm})+0.1] \mathrm{mm}$, for example, for a depth of $50 \mathrm{~mm}$, as used in the present study, the accuracy of measurement is $\pm 0.85 \mathrm{~mm}$. Throughout data collection an electrocardiogram (ECG) recorded heart rate allowing all images to be analysed at end-diastole, indicated by the peak of the ECG R wave (see Fig. 3a). To eliminate a

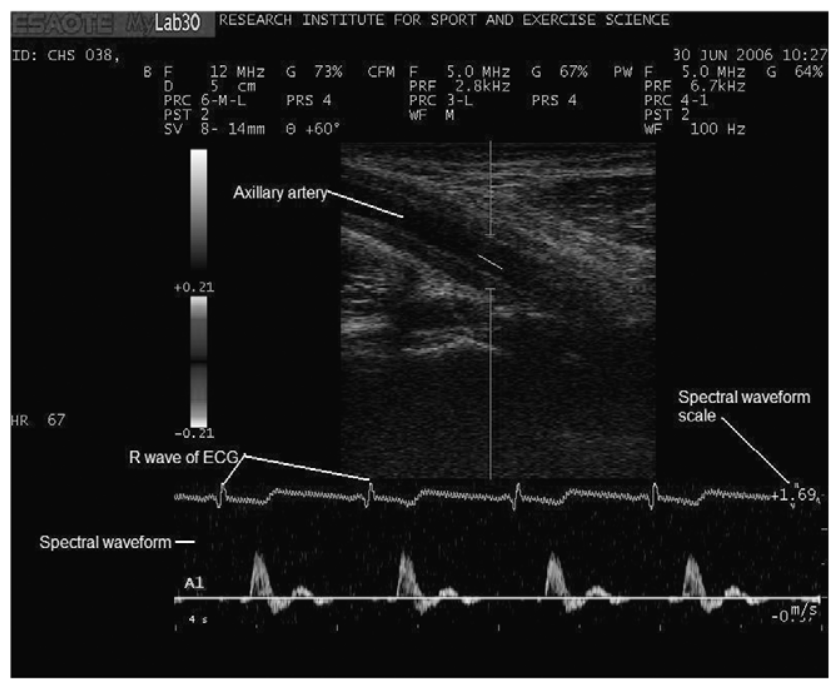

b

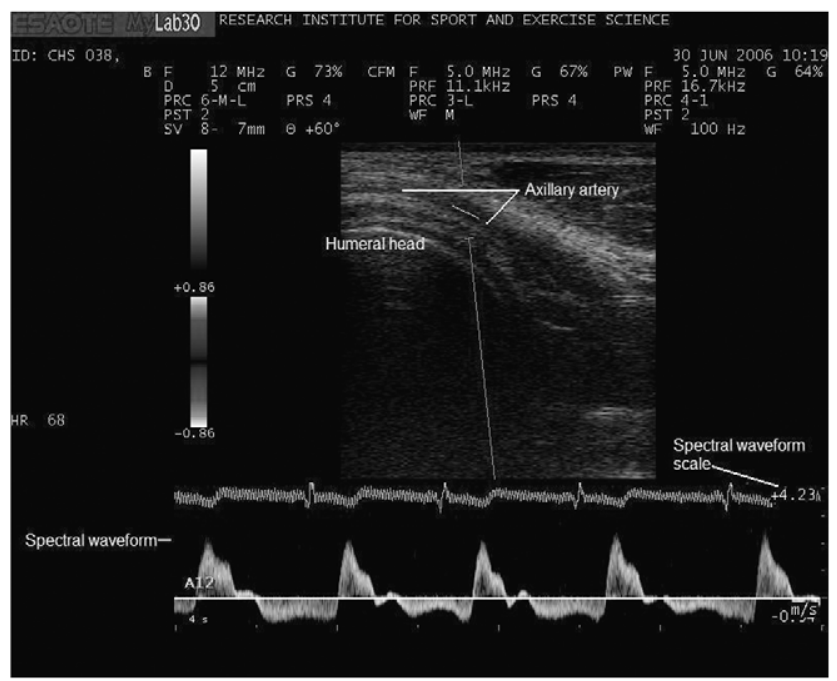

Fig. 3. B-mode and Doppler ultrasound for (a) baseline position and (b) position $12120^{\circ}$ abduction, $30^{\circ}$ horizontal extension, $90^{\circ}$ external rotation. Part (b) demonstrates compression of the axillary artery by the humeral head and an increased PSV, see spectral waveform scale compared to baseline.

intra-observer error, the same sonographer performed all scans and data analysis. The sonographer was blinded to subject identity and arm position for all sonographic image analyses. Intra-class correlation coefficients and coefficients of variation were determined in pilot work as $0.823(p<0.0005)$ and $15 \%$ for PSV, and $0.870(p<0.0005)$ and $6 \%$ for diameter measurements.

Following sonographic data collection for each arm position, subjects were questioned whether symptoms such as, pins and needles, numbness, coldness, pain/ache or any other sensation presented throughout the arm position. Any presenting sensations and their locations were recorded. 


\subsection{Statistical analysis}

In order to simulate diagnostic manoeuvres and the manner of their use in clinical practice, the data were grouped to allow comparison of arm positions either, progressively increasing in range or, progressively increasing in the combination of movements incorporated (see Table 1). Comparison group A determined the effects of abduction alone. The contribution of external rotation and horizontal flexion/extension were analysed within comparison groups $\mathrm{B}-\mathrm{E}$ and $\mathrm{F}-\mathrm{I}$, respectively. Where data met parametric assumptions one way repeated measures ANOVA with pair-wise comparisons and Bonferroni correction was used. In addition, where sphericity was violated, $F$ values were adjusted with the Greenhouse-Geisser correction. Data groups not meeting the criteria for normality of distribution were subject to transformation - the type (e.g., log and square root) indicated by the shape of the distribution curve (Tabachnick \& Fidell, 1996). Data sets failing transformation employed the non-parametric Friedman's test. The alpha level was set at 0.01 to reduce the risk of type I error prevalent with multiple analyses on the same sample.

To ascertain the incidence of individuals with responses that would, clinically, be defined as positive, Strandness's (2002) criteria was adopted. Reductions in diameter by at least $50 \%$, and a doubling of PSV, compared to baseline measures would be indicative of clinically significant arterial narrowing (Strandness, 2002).

\section{Results}

\subsection{Diameter}

The majority of arm positions revealed no change in vessel diameter, however, within comparison groups A and $\mathrm{E}$ arm position number's (APN) $3\left(120^{\circ}\right.$ abduction) and $4\left(180^{\circ}\right.$ abduction), and $11\left(120^{\circ}\right.$ abduction and $30^{\circ}$ horizontal extension) and $12\left(120^{\circ}\right.$ abduction, $90^{\circ}$ external rotation and $30^{\circ}$ horizontal extension), significant reductions were detected $[F(1.91$, $57.20)=19.932, \quad p<0.0005$ and $F(3,87)=10.706$, $p<0.0005$, respectively) (see Table 2 and Fig. 4). The mean percentage difference between baseline and each of these positions is greater than the coefficient of variation of $6 \%$ calculated from pilot work.

The mean axillary artery diameter for each arm position masks wide individual heterogeneity. Specifically, at APN 4, 3, and 12 at least $3(10 \%)$ subjects demonstrated clinically significant stenosis $(>50 \%$ diameter reduction) while, contrastingly, at least 5 $(16 \%)$ subjects demonstrated no signs of arterial diameter reduction (see Table 3).

\subsection{Peak systolic velocity}

The majority of arm positions did not result in any significant change in PSV. However, APN 3 and 11, previously identified as producing a significantly reduced vessel diameter, also exhibited significant changes in PSV. Friedman's test indicated significant differences within comparison groups $\mathrm{E}\left(p=0.008, \chi_{3,30}^{2}=12\right)$ and $\mathrm{H}\left(p=0.001, \chi_{3,31}^{2}=17\right)$. Further analyses with Wilcoxon tests revealed significant increases in PSV from baseline (median: $\left.77 \mathrm{~cm} \mathrm{~s}^{-1}\right)$ to APN $3\left(99 \mathrm{~cm} \mathrm{~s}^{-1}\right.$, $\left.p=0.001, \quad Z_{31}=-3.439\right)$ and APN $11\left(94 \mathrm{~cm} \mathrm{~s}^{-1}\right.$, $p<0.0005, Z_{31}=-3.312$ ) (see Fig. 4 and Table 4). These differences are greater than the coefficient of variation of $15 \%$ calculated from pilot data.

Consistent with diameter measures, wide heterogeneity existed in the sample population for PSV. For example, in APN 3,13\% of subjects demonstrated clinically significant doubling of the PSV whereas $26 \%$ demonstrated a reduction in PSV from baseline (see Table 5).

\subsection{Symptom production}

Despite rigorous screening of subjects, specific arm positions produced sensations such as paraesthesia, anaesthesia, coldness, heaviness, and achy pain. APN 4 and 12 reproduced the greatest incidence of symptoms at $52 \%$ and $42 \%$, respectively. To a lesser extent, other arm positions also elicited some symptoms in some individuals (see Fig. 4). However, no significant differences were detected between symptom free and symptom reporting individuals for median PSV or mean vessel diameter.

Table 2

Axillary artery mean diameter $\pm 95 \% \mathrm{CI}(\mathrm{mm})$ for each arm position

\begin{tabular}{|c|c|c|c|c|c|c|c|c|c|c|c|}
\hline APN & & & & & & & & & & & \\
\hline 1 & 2 & 3 & 4 & 5 & 6 & 7 & 8 & 9 & 10 & 11 & 12 \\
\hline $4.2 \pm 0.2$ & $4.3 \pm 0.2$ & $\begin{array}{l}3.6 \pm 0.3 \\
\text { レ }\end{array}$ & $\begin{array}{l}3.4 \pm 0.3 \\
\text { レ }\end{array}$ & $4.3 \pm 0.2$ & $4.2 \pm 0.2$ & $4.2 \pm 0.2$ & $4.1 \pm 0.2$ & $4.3 \pm 0.2$ & $4.1 \pm 0.3$ & $\begin{array}{l}3.7 \pm 0.3 \\
\text { レ }\end{array}$ & $3.4 \pm 0.3$ \\
\hline
\end{tabular}

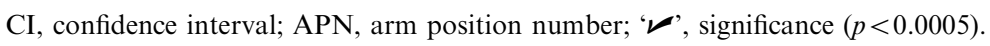




\section{Discussion}

Consistent with the findings of Mochizuki et al. (1994) and Rohrer et al. (1990), the present study's data reinforces the risk of false positive outcomes with shoulder manoeuvres at the extreme of range. Uniquely, however, the present study's data extends this risk to include diagnostic tests performed at $120^{\circ}$ abduction.

The current data demonstrated significant reductions in axillary artery diameter for APN's 3 ( $120^{\circ}$ abduction), $4\left(180^{\circ}\right.$ abduction $), 11\left(120^{\circ}\right.$ abduction with $30^{\circ}$ horizontal extension) and $12\left(120^{\circ}\right.$ abduction, $30^{\circ}$ horizontal extension, and $90^{\circ}$ external rotation). The characteristic responses of arterial diameter, PSV and blood flow to a narrowed arterial segment have been described by Spencer and Reid (1979). According to their theoretical model, reductions in vessel diameter result in corresponding increases in peak systolic velocity. This inverse relationship predicts that diameter reductions less than $20 \%$ will not greatly affect PSV. Theoretically, diameter reductions have to be greater than $50 \%$ before PSV changes will occur. In the present study, no rise in the group median PSV was seen for APN's $4\left(180^{\circ}\right.$ abduction) and $12\left(120^{\circ}\right.$ abduction, $30^{\circ}$ horizontal extension and $90^{\circ}$ external rotation) even though statistically significant reductions in vessel diameter were identified. This is due to the relatively small $(19 \%)$ reduction in mean diameter identified for
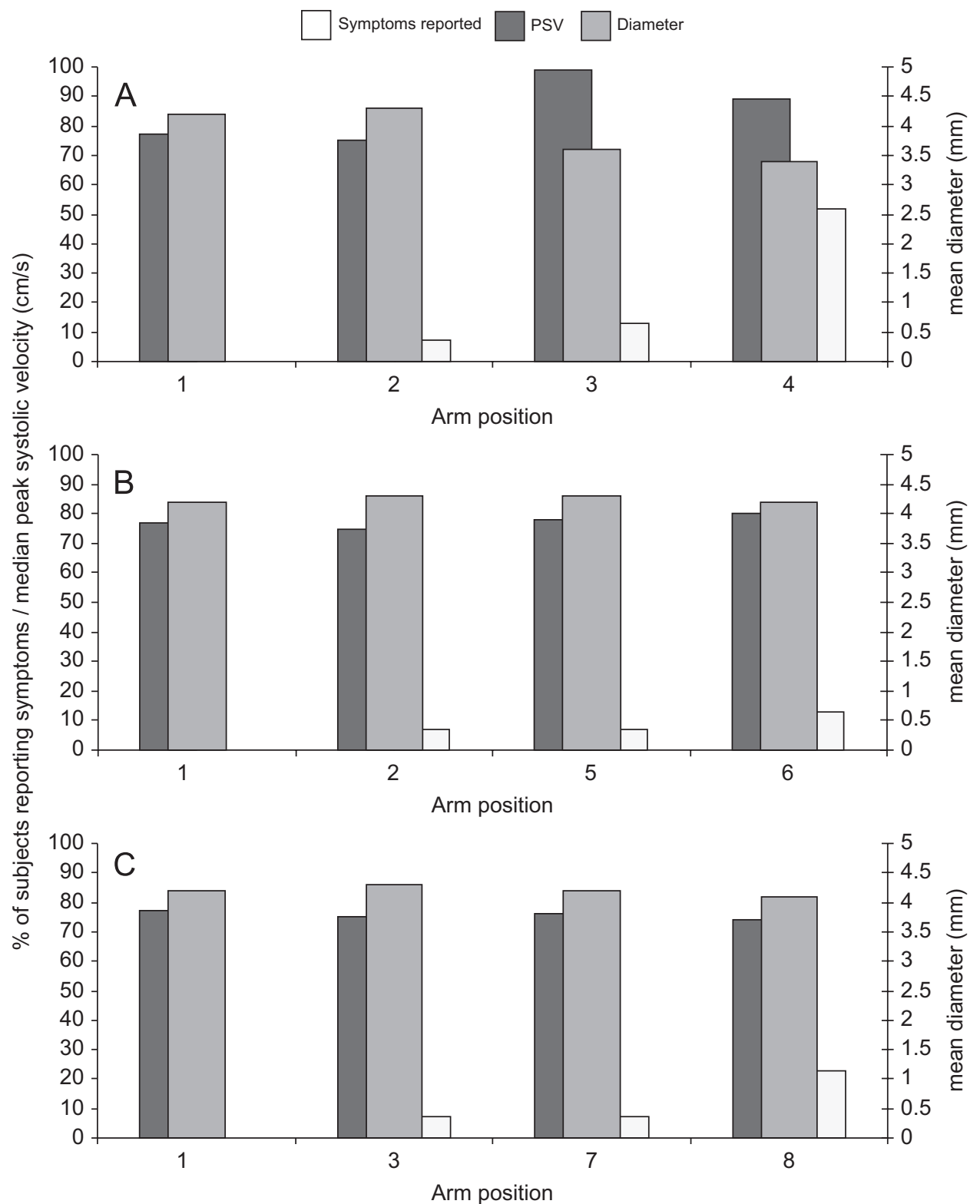

Fig. 4. Bar charts representing the relationship between the percentage of subjects reporting symptoms, median PSV and mean diameter for each arm position in their respective comparison group (A-I). 

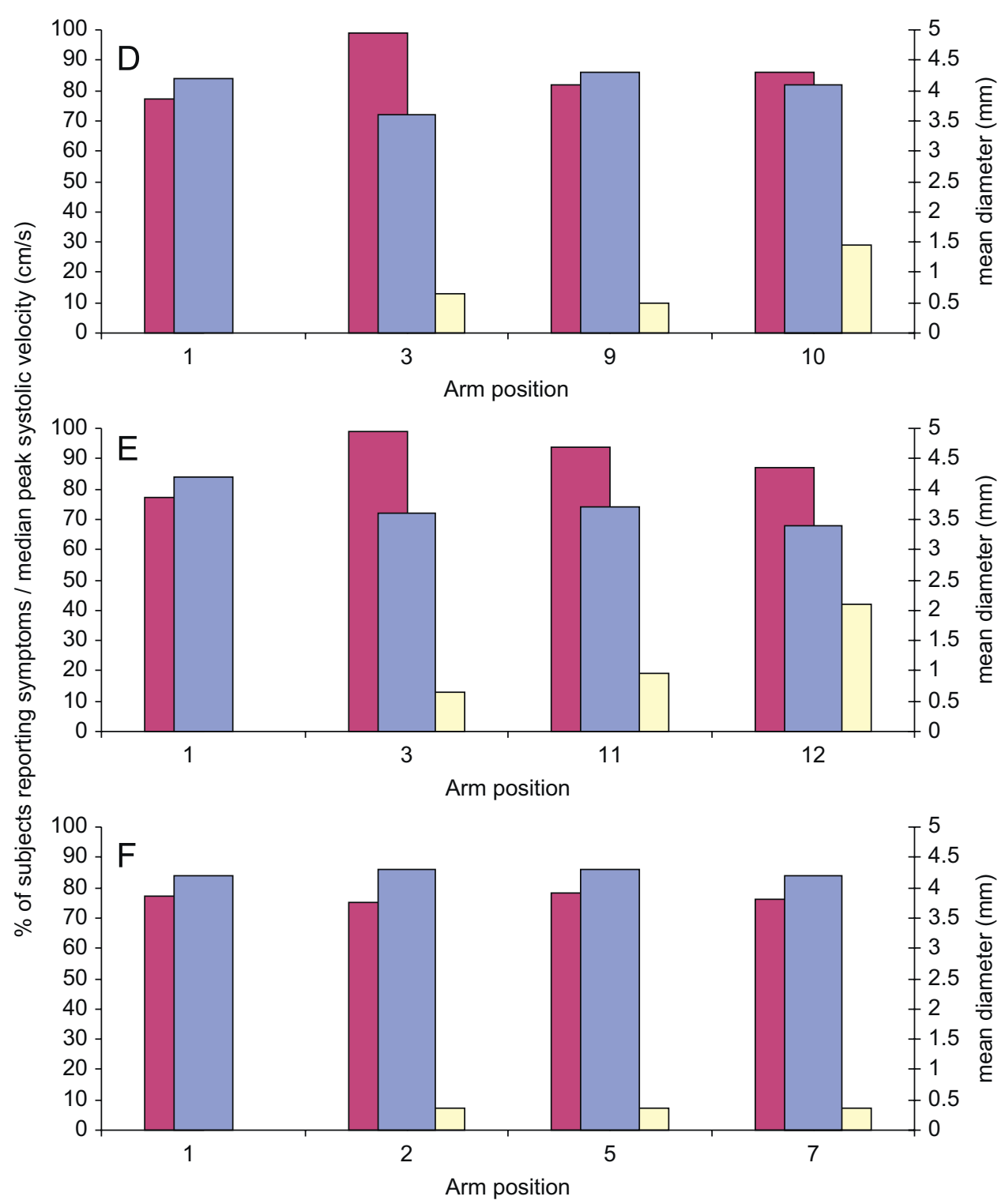

Fig. 4. (Continued)

APN's 4 and 12. However, it is most likely that the typical relationship between mean diameter and median PSV (Spencer \& Reid, 1979) were not observed for these APNs due to the extreme heterogeneity influencing the group mean and median, respectively.

Fig. $2 b$ depicts one possible cause of axillary artery diameter reduction, that is, compression by the humeral head. Translation of the humeral head was first suggested as a mechanism for axillary artery compromise by Dijkstra and Westra (1978) and a few case study reports (e.g., Finkelstein \& Johnston, 1993; Vlychou et al., 2001) supporting this mechanism have appeared in the literature. As the arm is abducted, the humeral head translates inferiorly (Graichen et al., 2000). The extent of translation is dictated by the resistance of the inferior glenohumeral joint (O'Brien et al., 1990). In addition, laxity of the anterior portion of the inferior glenohum- eral ligament results in excessive anterior translation when external rotation is performed (Harryman et al., 1990). In the present study, the addition of external rotation to $120^{\circ}$ abduction with $30^{\circ}$ horizontal extension (i.e., APN 12 compared to APN 11) resulted in $13 \%$ of subjects showing greater than $50 \%$ diameter reduction compared to $0 \%$ (see Table 3 ). This implies that, for some individuals, the action of external rotation at $120^{\circ}$ abduction and $30^{\circ}$ horizontal extension causes greater axillary artery compression. In support of Dijkstra and Westra (1978), Reekers et al. (1993), and Schneider et al. (1999), we postulate that the above mentioned translations create this compression of the axillary artery by translation of the humeral head.

In order to maximise repeatability, the present study attempted to consistently image the third portion of the axillary artery. It is feasible that some of the present 

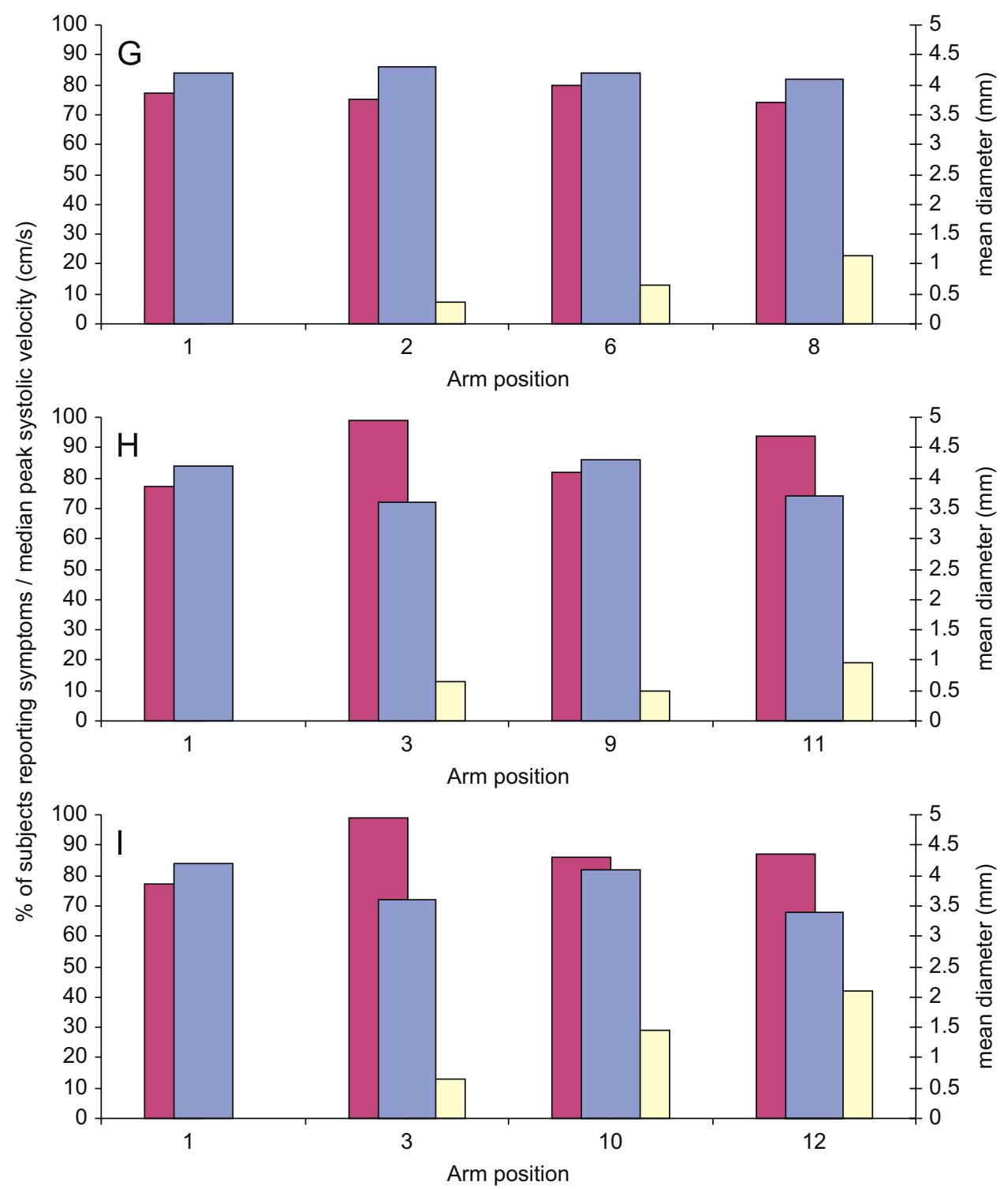

Fig. 4. (Continued)

Table 3

Percentage and number $(n)$ of subjects demonstrating no stenosis, less than $50 \%$ stenosis and clinically significant stenosis $(>50 \%$ diameter reduction)

\begin{tabular}{llll}
\hline Arm position & No stenosis & $<50 \%$ stenosis & $>50 \%$ stenosis \\
\hline 3 & $29(9)$ & $61(19)$ & $10(3)$ \\
4 & $16(5)$ & $68(21)$ & $16(5)$ \\
11 & $33(10)$ & $67(20)$ & $0(0)$ \\
12 & $27(8)$ & $60(18)$ & $13(4)$ \\
\hline
\end{tabular}

study's results may be indicative of proximal compression, where typically the PSV waveform appears dampened with spectral broadening. Proximal narrowing could be attributed to compression by the pectoralis minor muscle (Dijkstra \& Westra, 1978; Finkelstein \&
Johnston, 1993), anomalous anatomy (Smith \& Cummings, 2006), or compression of the subclavian artery at the costoclavicular space (Jackson, 2003). The result of combining data from direct and indirect sites of arterial compression may reduce the impact of an increased PSV, observed at the third portion of the axillary artery, on the group mean and is a limitation of this study.

Clinicians performing arm manoeuvres without advanced imaging technology interpret the reproduction of symptoms as a sign of a positive test (Plewa $\&$ Delinger, 1998). Interestingly, in the present study, the percentage of subjects reporting symptoms (for example, $52 \%$ for APN 4) outweighed the percentage with reduced blood flow characteristics (clinically significant changes for diameter $=16 \%$, and for PSV, $45 \%$ ). It is likely that a proportion of subjects expressing symptoms were a result of compression of neural or venous structures that 
Table 4

Axillary artery median peak systolic velocity and IQR $\left(\mathrm{cm} \mathrm{s}^{-1}\right)$ for each arm position

\begin{tabular}{|c|c|c|c|c|c|c|c|c|c|c|c|}
\hline \multicolumn{12}{|c|}{ Arm position } \\
\hline 1 & 2 & 3 & 4 & 5 & 6 & 7 & 8 & 9 & 10 & 11 & 12 \\
\hline \multirow[t]{2}{*}{77 (64-92) } & $75(64-86)$ & $99(84-118)$ & $89(50-110)$ & $78(67-95)$ & $80(71-98)$ & 76 (67-99) & $74(59-89)$ & 82 (69-98) & $86(65-98)$ & $94(81-121)$ & $87(61-111)$ \\
\hline & & $\nu$ & & & & & & & & $\nu$ & \\
\hline
\end{tabular}

IQR, inter-quartile range; ' $\boldsymbol{~ ' , ~ s i g n i f i c a n c e ~}(p \leqslant 0.001)$.

Table 5

Percentage and number $(n)$ of subjects demonstrating a doubling of PSV and a drop in PSV compared to the baseline value

\begin{tabular}{lll}
\hline Arm position & Doubling of PSV & Drop in PSV \\
\hline 3 & $13(4)$ & $26(8)$ \\
4 & $10(3)$ & $35(11)$ \\
11 & $6(2)$ & $23(7)$ \\
12 & $10(3)$ & $37(11)$ \\
\hline
\end{tabular}

accompany the arterial vasculature throughout its course. These results infer the possibility that diagnostic upper limb manoeuvres are not specific to arterial causes. Although clinically, obliteration of the radial pulse or, undetectable blood pressure, aids the diagnosis of arterial involvement they do not exclude coexisting nerve or venous compression. Clinically, comparison with the contralateral limb aids the conclusion of a positive test response. In this study, it was not considered necessary to compare results with the contralateral $\operatorname{limb}$ due to the asymptomatic and nonthrowing status of the subjects. In addition, the present study demonstrated no significant interaction between arm position and sex. These results were in keeping with those of Demondion et al.'s (2006) investigation on similar asymptomatic subjects where no significant difference was reported between males and females, or right and left sides.

The mean and median data presented masked wide heterogeneity for diameter and PSV in a sample of subjects rigorously screened for an absence of upper limb pathology. Specifically, at $120^{\circ}$ abduction, $30^{\circ}$ horizontal extension, and $90^{\circ}$ external rotation, $13 \%$ of subjects demonstrated a greater than $50 \%$ reduction in vessel diameter, $37 \%$ showed a drop in PSV, and $10 \%$ showed a doubling in PSV. The cause of such heterogeneity within the sample is unknown. We suggest that the following factors may contribute to the test response: hyper/hypomobility of the shoulder complex; forward shoulder posture/tight pectoralis minor; excessive anterior translation at the glenohumeral joint; and irregular, or anomalous, anatomy of the axillary artery and its subsidiaries. Further investigation of the relationship between such factors and test responses may aid identification of subjects predisposed to arterial compression syndromes and their subsequent management. A predisposition to arterial compression would be especially relevant in the overhead athlete population where repetitive compressive stress and altered haemodynamics may lead to arterial damage and the sequelae described in published case studies (Arko et al., 2001; Fields et al., 1986; Ishitobi et al., 2001; Rohrer et al., 1990; Todd et al., 1998; Vlychou et al., 2001).

\section{Conclusions}

From this study, we can conclude that vascular parameters were largely unaffected by arm movements in normal healthy adults. Only at end of range abduction and arm positions incorporating $120^{\circ}$ abduction were significant alterations recorded in vessel diameter, PSV, systolic BP, and symptom production. However, the mean values for each outcome masks widely heterogenous individual responses. At least $10 \%$ of subjects demonstrated diameter and PSV changes that would, clinically, be defined as positive. The cause and clinical relevance of these heterogenous responses from normal, healthy subjects warrants further investigation. Is it 'normal' for healthy, asymptomatic individuals to demonstrate axillary artery compression in specific overhead arm positions? Or, does it indicate a pre-clinical predisposition for a neurovascular compression syndrome?

The present study's results highlight the lack of specificity and differential diagnostic power of the hyperabduction manoeuvre using current clinical criteria (Strandness, 2002). It is postulated that combining the results of more than one test may increase specificity. This was investigated by Gillard et al. (2001) in the assessment of subclavian artery compression. Gillard et al. (2001) recommended a minimum of two provocative arm manoeuvres to increase specificity. The results of the present study reinforce the lack of specificity of one individual test and the necessity to integrate all information from a clinical assessment (i.e., clinical presentation, subjective history, physical examination, special tests, imaging results) to reduce the occurrence of misdiagnosis. 


\section{Conflict of Interest Statements}

None declared.

\section{Ethical Approval}

The organisation providing ethical approval and ethics protocol reference number where appropriate.

\section{References}

Arko, F. R., Harris, E. J., Zarins, C. K., \& Olcott, C. (2001). Vascular complications in high-performance athletes. Journal of Vascular Surgery, 33, 935-942.

Baker, C. L., \& Liu, S. H. (1993). Neurovascular injuries to the shoulder. Journal of Orthopaedic and Sports Physical Therapy, 18, 360-364.

Cormier, P. J., Matalon, T. A., \& Wolin, P. M. (1988). Quadrilateral space syndrome: A rare cause of shoulder pain. Radiology, 167, 797-798.

Demondion, X., Vidal, C., Herbinet, P., Gautier, C., Duquesnoy, B., \& Cotten, A. (2006). Ultrasonographic assessment of arterial crosssectional area in the thoracic outlet on postural maneuvers measured with power Doppler ultrasonography in both asymptomatic and symptomatic populations. Journal of Ultrasound in Medicine, 25, 217-224.

Dijkstra, P. F., \& Westra, D. (1978). Angiographic features of compression of the axillary artery by the musculus pectoralis minor and the head of the humerus in the thoracic outlet compression syndrome. Case report. Radiologia Clinica, 47, 423-427.

Durham, J. R., Yao, J. S., Pearce, W. H., Nuber, G. M., \& McCarthy, W. J., 3rd (1995). Arterial injuries in the thoracic outlet syndrome. Journal of Vascular Surgery, 21, 57-69.

Fields, W. S., Lemak, N. A., \& Benmenachem, Y. (1986). Thoracic outlet syndrome - Review and reference to stroke in a major-league pitcher. American Journal of Neuroradiology, 7, 73-78.

Finkelstein, J. A., \& Johnston, K. W. (1993). Thrombosis of the axillary artery secondary to compression by the pectoralis minor muscle. Annals of Vascular Surgery, 7, 287-290.

Gillard, J., Perez-Cousin, M., Hachulla, E., Remy, J., Hurtevent, J. F., Vinckier, L., et al. (2001). Diagnosing thoracic outlet syndrome: Contribution of provocative tests, ultrasonography, electrophysiology, and helical computed tomography in 48 patients. Joint, Bone, Spine: Revue du Rhumatisme, 68, 416-424.

Graichen, H., Stammberger, T., Bonel, H., Karl-Hans, E., Reiser, M., \& Eckstein, F. (2000). Glenohumeral translation during active and passive elevation of the shoulder-A 3d open-MRI study. Journal of Biomechanics, 33, 609-613.

Harryman, D. T., 2nd, Sidles, J. A., Clark, J. M., McQuade, K. J., Gibb, T. D., \& Matsen, F. A., 3rd (1990). Translation of the humeral head on the glenoid with passive glenohumeral motion. Journal of Bone and Joint Surgery (Am), 72A, 1334-1343.

Ishitobi, K., Moteki, K., Nara, S., Akiyama, Y., Kodera, K., \& Kaneda, S. (2001). Extra-anatomic bypass graft for management of axillary artery occlusion in pitchers. Journal of Vascular Surgery, 33, 797-801.
Jackson, M. R. (2003). Upper extremity arterial injuries in athletes. Seminars in Vascular Surgery, 16, 232-239.

Kee, S. T., Dake, M. D., Wolfe-Johnson, B., Semba, C. P., Zarins, C. K., \& Olcott, C. (1995). Ischemia of the throwing hand in major league baseball pitchers: Embolic occlusion from aneurysms of axillary artery branches. Journal of Vascular and Interventional Radiology, 6, 979-982.

Mochizuki, T., Isoda, H., Masui, T., Ohkawa, Y., Takahashi, M., Takehara, Y., et al. (1994). Occlusion of the posterior humeral circumflex artery-Detection with MR angiography in healthyvolunteers and in a patient with quadrilateral space syndrome. American Journal of Roentgenology, 163, 625-627.

Nijhuis, H. H., \& Muller-Wiefel, H. (1991). Occlusion of the brachial artery by thrombus dislodged from a traumatic aneurysm of the anterior humeral circumflex artery. Journal of Vascular Surgery, 13, 408-411.

O'Brien, S. J., Neves, M. C., Arnoczky, S. P., Rozbruck, S. R., Dicarlo, E. F., Warren, R. F., et al. (1990). The anatomy and histology of the inferior glenohumeral ligament complex of the shoulder. American Journal of Sports Medicine, 18, 449-456.

Plewa, M. C., \& Delinger, M. (1998). The false-positive rate of thoracic outlet syndrome shoulder maneuvers in healthy subjects. Academic Emergency Medicine, 5, 337-342.

Redler, M. R., Ruland, L. J., 3rd, \& McCue, F. C., 3rd (1986). Quadrilateral space syndrome in a throwing athlete. American Journal of Sports Medicine, 14, 511-513.

Reekers, J. A., den Hartog, B. M., Kuyper, C. F., Kromhout, J. G., \& Peeters, F. L. (1993). Traumatic aneurysm of the posterior circumflex humeral artery: A volleyball player's disease? Journal of Vascular and Interventional Radiology, 4, 405-408.

Rohrer, M. J., Cardullo, P. A., Pappas, A. M., Phillips, D. A., \& Wheeler, H. B. (1990). Axillary artery compression and thrombosis in throwing athletes. Journal of Vascular Surgery, 11, 761-768.

Schneider, K., Kasparyan, N. G., Altchek, D. W., Fantini, G. A., \& Weiland, A. J. (1999). An aneurysm involving the axillary artery and its branch vessels in a major league baseball pitcher: A case report and review of the literature. American Journal of Sports Medicine, 27, 370-375.

Smith, R. A., Jr., \& Cummings, J. P. (2006). The axillary arch: Anatomy and suggested clinical manifestations. Journal of Orthopaedic and Sports Physical Therapy, 36, 425-429.

Spencer, M. P., \& Reid, J. M. (1979). Quantitation of carotid stenosis with continuous-wave (C-W) Doppler ultrasound. Stroke, 10, 326-330.

Strandness, D. (2002). Hemodynamics of arterial stenosis and occlusion. In D. Strandness (Ed.), Duplex scanning in vascular disorders (3rd ed., p. 68). Lippincott Williams and Wilkins.

Tabachnick, B., \& Fidell, L. (1996). Normality, linearity, and homoscedasticity. In B. Tabachnick, \& L. Fidell (Eds.), Using multivariate statistics (4th ed., p. 82). New York: Harper Collins.

Todd, G. J., Benvenisty, A. I., Hershon, S., \& Bigliani, L. U. (1998). Aneurysms of the mid axillary artery in major league baseball pitchers-A report of two cases. Journal of Vascular Surgery, 28, 702-707.

Vlychou, M., Spanomichos, G., Chatziioannou, A., Georganas, M., \& Zavras, G. M. (2001). Embolisation of a traumatic aneurysm of the posterior circumflex humeral artery in a volleyball player. British Journal of Sports Medicine, 35, 136-137.

Wright, I. (1945). The neurovascular syndrome produced by hyperabduction of the arm. American Heart Journal, 29, 1-19. 